\title{
The Role of University Support Services on Academic Outcomes for Students with Mental Illness
}

\author{
Andrea Simpson and Kerry Ferguson \\ School of Communication Sciences, La Trobe University, Melbourne, VIC 3000, Australia \\ Correspondence should be addressed to Andrea Simpson; a.simpson@latrobe.edu.au
}

Received 28 July 2014; Revised 14 October 2014; Accepted 19 October 2014; Published 11 November 2014

Academic Editor: Lieven Verschaffel

Copyright (C) 2014 A. Simpson and K. Ferguson. This is an open access article distributed under the Creative Commons Attribution License, which permits unrestricted use, distribution, and reproduction in any medium, provided the original work is properly cited.

\begin{abstract}
Mental illness in the university student population has come under increased scrutiny in recent years. Students with mental illness are understandably highly reluctant to disclose their condition to others due to fear of prejudice, "not blending in," and a strong desire to appear self-reliant. This study considered whether disclosure to university support services, with all its perceived risks, had academic benefits for students with mental illness. Preliminary evidence was found that, for those students with mental illness who registered with the University's Disability Support Service for assistance, academic achievement was significantly higher on average in the year following their joining the service. Academic retention for these students was comparable to their university peers. A number of recommendations are discussed that could accommodate for students' learning needs, thereby benefitting those experiencing mental health difficulties.
\end{abstract}

\section{Introduction}

Over the past few decades, mental illness in the university student population has been on the rise in both prevalence and complexity [1-3]. With many institutions looking to expand student enrolments as well as diversity, we can only anticipate that this trend will continue to increase with larger student numbers.

Young adulthood is the age when mental illness symptoms typically first begin to appear and the effects of illness can have highly disruptive consequences on a young person's education and employment outcomes. Poor mental health directly affects academic performance with students with mental illness reporting difficulties with motivation, concentration, and confidence, all of which impact negatively on the ability to persist and succeed in a tertiary environment [4]. Individuals with mental illness can also find it difficult to cope with the demands of study together with their illness and are often forced to take time out of their daily commitments to manage their condition [5].

To assist students with mental illness in persisting in their study, educational institutions offer a range of support programs and services, including counselling and disability support. These support services are common to a number of higher education institutions and provide psychotherapeutic single and group sessions as well as practical learning support such as linking the student with other services, advice on reasonable adjustment for assignments and exams, notetakers, accessible course material, and assistive learning technologies.

However, in order to access these additional supports, students with mental illness must seek help from the institution themselves, thereby disclosing their condition to others. From an institutional perspective, "asking for help" is linked with the idea that the student has some acceptance of their condition and is therefore willing to work with others to achieve their study goals [6].

Yet, for the student, the decision to disclose their condition is not an easy one. Students who register with the Disability Support Service at the author's institution with mental illness have to be not only comfortable in disclosing their condition to others, but also prepared to identify as having a "disability" - a term many still associate with social stigma. Venville and Street [6] write how students with mental illness are highly reluctant to disclose their condition 
to their institution due to fear of prejudice, "not blending in," and a strong desire to appear self-reliant. Students in their study described how they carefully weighed up the risks of disclosure with its potential benefits. Due to the nature of mental illness, many students were often unable to ask for help when they most needed it.

Disclosure and its perceived risks result in far fewer students approaching services who could have benefitted from them. Furr et al. [7] estimate that only 20 percent of the numbers of students in higher education who need support actually seek help. In Australia's Vocational Education and Training (VET) sector, only 1.2 per cent of the student body disclosed a mental illness. Comparatively, national surveys have found that approximately 26 per cent of Australian young people experience mental illness [5].

Many students with mental illness also remain unconvinced that joining a support service would assist them academically [6]. The numbers of students turning up at an institution's support services are thus a highly conservative estimate of the total number of students who could benefit from further support.

Of interest then is whether disclosure, with all its perceived risks, does indeed "pay off" for students with mental illness. In studies on counselling services in higher education, both Wilson et al. [8] and Rickinson and Rutherford [9] found a positive correlation between the number of counselling sessions attended and student retention. However, it is unclear from these studies the reasons students attended counselling and whether these students experienced mental illness per se. Very little is known on the interaction between mental illness, tertiary services, and academic outcomes, particularly services such as disability support services, which provide learning support, rather than psychotherapeutic intervention. If the benefits of disclosure outweigh the risks, more students may be inclined to take up support services.

The authors were interested in further exploring the topic of "disclosure" with particular reference for our own institution's Disability Support Service. Particularly, the study sought to address the questions of whether disclosure of mental illness to the Disability Support Service has increased in recent years, whether the types of students who disclosed to the service differed from their peers, and whether the service benefitted students with regard to academic outcomes.

A list of student identification numbers for students who were newly registered with the Disability Support Service over 2008-2011 was extracted from the service's database. In order for a student to be classified with "mental illness" with the service some form of medical confirmation of diagnosis is required. Accepted documentation includes a letter or report from the student's GP or specialist or a medical certificate stating the student's condition. The list of students was then matched with demographic and academic enrolment information in the University's student administration database. The following information was requested from the database: gender, age, course load, study commencement year, campus of enrolment, and course-weighted average for every year of study. The study was approved by La Trobe University's Human Ethics Committee (Application number 12-060).

\section{Results}

2.1. Rates of Disclosure. A total of 1,522 newly registered students were entered into the Disability Support Service's database over 2008-2011. The numbers of students approaching the service have steadily increased over the past four years from a total of 277 students in 2008 to 529 students in 2011. This appears to be most likely due to a corresponding increase in student numbers at the University over the past decade, although there is some evidence that a greater proportion of students are now disclosing their disability than they were in the past. The percentage of the total student body who disclosed a disability to the service was only 1 per cent in 2008 , which doubled to 2 per cent in 2011.

Mental illness was the most prevalent condition reported to the service with 681 students (38 per cent) presenting to the service disclosing mental illness. The most common conditions reported were anxiety and depression with threequarters of the students with mental illness experiencing one or both of these conditions. Approximately 9 per cent of those students with mental illness reported bipolar disorder and 4 per cent reported schizophrenia.

As for overall numbers, the representation of newly registered students presenting at the service with mental illness also appeared to be on the rise. In 2008, approximately 41 per cent of students presenting to the service reported a mental illness. In 2011, 45 per cent of the total number of newly registered students who were recorded in the database reported mental illness. However, overall student number disclosing mental illness to the service remains extremely low at just 1 per cent of the total student body.

\subsection{Demographic Profile of Students Who Disclosed Mental} Illness. The demographic breakdown for the 681 students with mental illness who registered with the Disability Support Service is shown in Table 1. The analysis found that the majority of students did not register with the service during their first year of study with only 35 per cent of the study cohort registered with the service during this time. The remainder joined the service during their $2 \mathrm{nd}$, $3 \mathrm{rd}$, or 4 th year of study. The majority of students were full-time, city-based, and undergraduate, which is representative of the University's wider student body. Greater numbers of female and "matureaged" students (25 years of age and above) were represented in the study cohort when compared to the University's student body. In 2011, the University's student body consisted of 62 per cent female students and 31 per cent mature-aged students. For those students who disclosed mental illness, approximately 70 per cent were female and 43 per cent were mature-aged. International students were seen in particularly low numbers at only 5 per cent of the study cohort, especially considering that the representation of international students within the University's wider student body is approximately 23 per cent.

2.3. Academic Outcomes. Academic retention for the study cohort was calculated as the proportion of students who were studying in a given year that returned in the following year, excluding those that completed their studies. Results 
TABLE 1: Demographic profile of the 681 students with mental illness who registered with the University's Disability Support Service.

\begin{tabular}{|c|c|c|}
\hline Variable & Number & Percentage \\
\hline \multicolumn{3}{|c|}{ Gender } \\
\hline Female & 484 & $70 \%$ \\
\hline \multicolumn{3}{|c|}{ International student } \\
\hline Yes & 34 & $5 \%$ \\
\hline \multicolumn{3}{|c|}{ Attendance type } \\
\hline Full-time & 434 & $64 \%$ \\
\hline \multicolumn{3}{|c|}{ Age group } \\
\hline $17-24$ years & 385 & $57 \%$ \\
\hline$>25$ years & 296 & $43 \%$ \\
\hline \multicolumn{3}{|c|}{ Location } \\
\hline City & 471 & $69 \%$ \\
\hline Regional & 210 & $31 \%$ \\
\hline \multicolumn{3}{|c|}{ Course level } \\
\hline Undergraduate & 621 & $91 \%$ \\
\hline \multicolumn{3}{|c|}{ Year of registration with service } \\
\hline 1st year of study & 236 & $35 \%$ \\
\hline 2nd year of study & 190 & $28 \%$ \\
\hline 3rd year of study & 139 & $20 \%$ \\
\hline 4 th year of study & 113 & $17 \%$ \\
\hline
\end{tabular}

TABLE 2: Academic retention rates for the study cohort as compared to the wider student body.

\begin{tabular}{lcccc}
\hline Year/s & Base & Retained & $\begin{array}{c}\text { Cohort } \\
\text { retention rate }\end{array}$ & $\begin{array}{c}\text { University } \\
\text { retention rate }\end{array}$ \\
\hline $06-07$ & 100 & 83 & $83 \%$ & $83 \%$ \\
$07-08$ & 154 & 141 & $92 \%$ & $83 \%$ \\
$08-09$ & 270 & 243 & $90 \%$ & $82 \%$ \\
$09-10$ & 366 & 302 & $83 \%$ & $79 \%$ \\
$10-11$ & 415 & 329 & $79 \%$ & $80 \%$ \\
\hline
\end{tabular}

are shown in Table 2. For comparison, the wider University's retention rates for each academic year are shown in the far right-hand column. The study cohort was found to have retention rates that were comparable or higher than the University average.

The impact of joining the service was also found to have a positive effect on academic achievement. To determine whether the Disability Support Service had an impact on academic achievement, students' course-weighted average in the year prior to registering with the service (before intervention) was compared to student's course-weighted average in the years during and after registering with the service (at and after intervention). Results between pre- and post-intervention were analysed using paired $t$-tests and are shown in Figure 1.

The course weighted average before intervention for the group was 54 per cent $(N=492)$, which increased to 59 per cent $(N=466)$ in the year of intervention. This difference in scores was found to be statistically significant $(P \leq 0.001$, $t=6.8 \mathrm{df}=465)$. In the year after intervention, students'

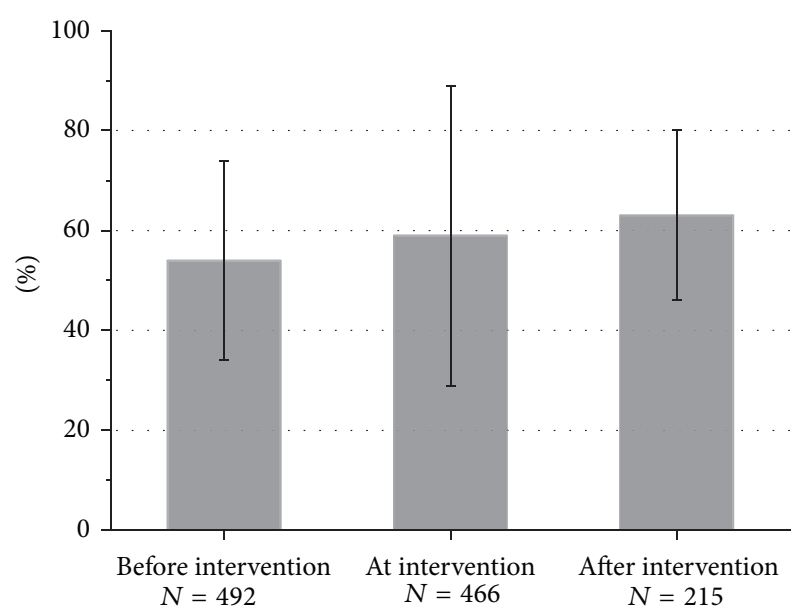

FIGURE 1: Average academic scores for the study cohort before, at, and after intervention. Error bars indicate one standard deviation.

average results were 63 per cent $(N=215)$, higher than the University average of 60 per cent. The jump in academic results pre-to-post intervention was also found to be highly statistically significant $(P \leq 0.001, t=7.4, \mathrm{df}=214)$, as was the differences in scores at the year of intervention when compared to the year after intervention $(P \leq 0.001, t=4.5$, $\mathrm{df}=214)$.

\section{Discussion}

The interpretation of findings for this paper are limited in a number of ways. Firstly the authors did not carry out an analysis comparing students with mental illness to the wider cohort of students with other health conditions. Equally, a useful comparison would have been to contrast retention and academic achievement for the subset of service users disclosing mental illness to the Disability Support Service as well as to the University's counselling service. Finally, the analysis is limited by a relatively small number of students with mental illness compared to a much larger cohort of the wider University population. This weakens statistical comparisons between the two groups.

Nonetheless, the decision to register with the University's Disability Support Service appears to have had a positive impact on students' academic results. Retention figures for students with mental illness appear to be at a minimum comparable to the wider student cohort. These findings are encouraging considering that psychological symptoms are a significant predictive factor of student retention [3, 10]. "Emotional health" has been the highest rated reason contributing to student attrition in Australia's Centre of the Study of Higher Education (CSHE) student experience survey in 1999, 2004, and 2009 [11]. Students experiencing mental illness, and who remain untreated, are thus far more likely to leave university before completing their studies.

Students may have benefitted from both the learning supports offered and ongoing contact with staff. The results support findings from a qualitative study with five university students experiencing mental illness, where the students 
described positively how the practical supports offered by disability support staff assisted them in their studies [12]. Students in the study also reported feeling to attend the service regularly to discuss their academic progress, whereas campus counselling had only been able to offer them a few sessions due to limited capacity. Certainly at our own institution, counseling is a high demand service under pressure to deliver short-term interventions. It is possible that if students with mental illness perceive that they have used their "allocated quota" from counseling services, they would turn to the disability support service for regular contact, using staff as a "case worker" of sorts.

Whilst encouraging, the results should be interpreted with some caution. We cannot say for certain that joining the service was the sole reason for the increase in students' performance. The findings do not show causality as they cannot be isolated from other variables in the students' lives. Other factors, which may have contributed to the improvement in scores, could be that at the time students' register with the service they are also undergoing a number of other interventions to assist in managing their illness, for example, diagnosis, medication, linking in with other services and professionals, and so on. In addition, the analysis has the limitation that students may have naturally improved their study and learning skills over time although this is somewhat compensated for by the fact that students within the study were at varying points within their degrees.

\section{Implications for Practice}

Further evidence is needed to understand the links between service usage and academic outcomes. Even if these were more widely understood, institutions' biggest challenge is in knowing that only very small numbers of students are comfortable in disclosing their condition. When compared to the wider student body and estimates of mental illness in the general population, students with mental illness are underutilizing support services. In the current study only 1 per cent of the total student body disclosed a mental illness to the service.

Universities would need to come up with innovative ways of reaching out to the larger numbers of nondisclosed students. Students' concerns about disclosure are justified when considering the sociocultural prejudice associated with mental illness. A conundrum for the university then is the desire to increase disclosure rates in order to offer support, whilst at the same time respecting that many students may never wish to disclose their condition.

In order to assist those students experiencing mental illness, the university community may benefit from a number of short- and long-term interventions. Firstly, institutions need to tackle the culture of stigma and facilitate better understanding of the importance and role of mental health in wellbeing. There are a number of ways in which institutions could build greater awareness about mental health and its impact on study, work, and life. Pinfold et al. [13] describe how focus groups including narratives from mental illness sufferers have been an effective means of reducing workplace stigma. Many institutions offer mental health first aid training and literacy for their staff. In this way members of the university community are better equipped to seek help for themselves and support others experiencing mental illness.

These awareness-raising strategies could incorporate targeting of specific student groups. This study was not alone in finding that support services appeal to certain students more than others with female, older, and local students far more likely to disclose their condition. Women have been found to be more positive than men about mental illness treatment [14] and generally more likely than men to use campus counselling services $[15,16]$. Younger adults have also been found to use services less than older adults [14].

In a study on perceived stigma and help-seeking intention, Eisenberg et al. [17] found that personal stigma of mental illness was higher in male, younger, and international students. Personal stigma was also found to be negatively correlated with help-seeking intention. International students in particular have been found to underutilize university support services $[16,18,19]$. Barriers for these students in seeking institutional supports have included poorer language proficiency, cultural stigma, and shame associated with mental illness. These students have also been found to seek support from family and friends in the first instance before turning to institutional supports $[18,19]$.

Services therefore need to develop ways of reaching those students who do not traditionally seek help. Wechsler et al. [20], for instance, describe how social-norm campaigns, commonly used on campuses to encourage moderating alcohol intake, can successfully change attitudes and behaviors by providing information about common misconceptions. For example, if students knew that the majority of their peers experienced some form of mental illness, and that they would not think less of someone for seeking support, this may encourage students to seek help for themselves.

Universities should also carefully consider the wording they use to label services, what happens to medical information that is collected, and whether this is inclusive of students with mental illness. A number of authors have raised concerns that many students with mental illness do not identify their condition with the word "disability" and therefore do not "tick the box" $[6,21]$. For those students who do decide to disclose, the organizational processes associated with what happens to this information needs to be made clearer. Students have been found to disclose their condition only to find that "nothing happens." Venville and Street [6] recommend that organisations clarify whether medical information is used purely for organisational statistical reporting, or rather if will be used to link students in with supports.

Support services must therefore plan the ways in which they are communicating to students and the processes under which students are able to access the service. For instance, an incorrect assumption is that students with mental illness will disclose their condition during their enrollment. In the current study, only 35 per cent of the cohort disclosed during their first year of study. In the United Kingdom's report on uptake of the higher education disability student allowance, only 42 per cent of students with a disability disclosed during the application process [22]. The remaining students may only decide to disclose once they are experiencing academic 
difficulty or may develop their condition once their studies have already begun.

These findings have implications for whom, how, and when services engage with the student body. In order to combat this, the United Kingdom's Equality Challenge Unit recommends that information about support needs to be provided more than once, at multiple times in the student journey, and in a variety of ways to ensure that awareness is raised [22]. Students need to be provided with more than one opportunity to approach the organization for assistance. Information about support services could also be linked in with current strategies to identify students "at risk" of academic disengagement.

Finally, no matter how effective a university's communication and awareness strategies, there will always be students who would choose not to disclose their condition. Although cultural acceptance as well as accommodation of the impact of mental illness is the eventual aim, this process will not happen quickly. In the shorter term, universities should incorporate inclusive policies that could accommodate for all students' learning needs, thereby benefitting those experiencing mental illness. These are not necessarily costly or difficult to implement. This study has found some evidence to suggest that the simple, practical assistance offered by the Disability Support Service such as assignment extension on request and alternative assessment techniques could have positive academic impacts for students. Changes to the curriculum to make it more inclusive of all students offer a way for students to manage their condition at times when they need it most.

\section{Conclusions}

The number of students disclosing a disability to the University's Disability Support Service has doubled over the past few years, with mental illness accounting for almost 40 per cent of the kinds of conditions reported. For those students who registered with the Disability Support Service for assistance with their mental illness, students' academic achievement was approximately 10 percentage points higher on average in the year following their joining the service. Retention rates were also comparable to University averages. These results provide encouraging evidence of the benefits of seeking assistance from university support services.

\section{Conflict of Interests}

The authors declare that there is no conflict of interests regarding the publication of this paper.

\section{Acknowledgments}

Thanks go to the following colleagues for providing assistance with this research: Ms. Shannon Kerrigan, Mr. Ian Atkinson, Mr. Michael Luckman, and Dr. Andrew Harvey.

\section{References}

[1] S. A. Benton, J. M. Robertson, W. Tseng, F. B. Newton, and S. L. Benton, "Changes in counseling center client problems across
13 years," Professional Psychology: Research and Practice, vol. 34, no. 1, pp. 66-72, 2003.

[2] L. J. Cook, "Striving to help college students with mental health issues," Journal of Psychosocial Nursing and Mental Health Services, vol. 45, no. 4, pp. 40-44, 2007.

[3] T. M. Osberg, "A business case for increasing college mental health services," Behavioural Health Management, vol. 24, no. 5, pp. 33-36, 2004.

[4] LTU, Meeting the Needs of Students with Mental Health Issues, La Trobe University Counselling Services, La Trobe University, Melbourne, Australia, 2007.

[5] ABS, Mental Health of Young People, Australian Bureau of Statistics, Canberra, Australia, 2007.

[6] A. Venville and A. Street, Unfinished Business: Student Perspectives on Disclosure of Mental Illness and Success in VET, National Vocational Education and Training Research and Evaluation Program, and the Department of Education, Employment, and Workplace Relations, Commonwealth of Australia, Canberra, Australia, 2012.

[7] S. R. Furr, G. N. McConnell, J. S. Westefeld, and J. M. Jenkins, "Suicide and depression among college students: a decade later," Professional Psychology: Research and Practice, vol. 32, no. 1, pp. 97-100, 2001.

[8] S. B. Wilson, T. W. Mason, and M. J. M. Ewing, "Evalutating the impact of receiving university-based counseling services on student retention," Journal of Counseling Psychology, vol. 44, no. 3, pp. 316-320, 1997.

[9] B. Rickinson and D. Rutherford, "Increasing undergraduate student retention rates," British Journal of Guidance and Counselling, vol. 23, no. 2, pp. 161-172, 1995.

[10] S. Fisher and B. Hood, "The stress of the transition to university: a longitudinal study of psychological disturbance, absentmindedness and vulnerability to homesickness," The British Journal of Psychology, vol. 78, pp. 425-441, 1987.

[11] R. James, K. Krause, and C. Jennings, The First Year Experience in Australian Universities: Findings from 1994 to 2009, Centre for the Study of Higher Education, The University of Melbourne and Griffith Institute for Higher Education, Griffith University, Melbourne, Australia, 2010.

[12] T. Tinklin, S. Riddell, and A. Wilson, "Support for students with mental health difficulties in higher education: the students perspective," The British Journal of Guidance and Counselling, vol. 33, no. 4, pp. 495-512, 2005.

[13] V. Pinfold, G. Thornicroft, P. Huxley, and P. Farmer, "Active ingredients in anti-stigma programmes in mental health," International Review of Psychiatry, vol. 17, no. 2, pp. 123-131, 2005.

[14] R. Mojtabai, M. Olfson, and D. Mechanic, "Perceived need and help-seeking in adults with mood, anxiety, or substance use disorders," Archives of General Psychiatry, vol. 59, no. 1, pp. 77$84,2002$.

[15] J. Connell, M. Barkham, and J. Mellor-Clark, "CORE-OM mental health norms of students attending university counselling services benchmarked against an age-matched primary care sample," British Journal of Guidance and Counselling, vol. 35, no. 1, pp. 41-57, 2007.

[16] A. Raunic and S. Xenos, "University counselling service utilisation by local and international students and user characteristics: a review," International Journal for the Advancement of Counselling, vol. 30, no. 4, pp. 262-267, 2008.

[17] D. Eisenberg, M. F. Downs, E. Golberstein, and K. Zivin, "Stigma and help seeking for mental health among college 
students," Medical Care Research and Review, vol. 66, no. 5, pp. 522-541, 2009.

[18] T. Morgan, D. Ness, and M. Robinson, "Students' help-seeking behavious by gender, racial background, and student status," Canadian Journal of Counselling, vol. 37, no. 2, pp. 151-162, 2003.

[19] J. E. Nilsson, L. A. Berkel, L. Y. Flores, and M. A. Lucas, "Utilisation rate and presenting concerns of international students at a university counselling centre: implications for outreach programming," Journal of College Student Psychotherapy, vol. 19, no. 2, pp. 49-59, 2004.

[20] H. Wechsler, T. F. Nelson, J. E. Lee, M. Seibring, C. Lewis, and R. P. Keeling, "Perception and reality: a national evaluation of social norms marketing interventions to reduce college students' heavy alcohol use," Journal of Studies on Alcohol, vol. 64, no. 4, pp. 484-495, 2003.

[21] N. Quinn, A. Wilson, G. Macintyre, and T. Tinklin, "People look at you differently': Students' experience of mental health support within higher education," British Journal of Guidance and Counselling, vol. 37, no. 4, pp. 405-418, 2009.

[22] ECU, Evidencing Equality: Approaches to Increasing Disclosure and Take-Up of Disabled Students' Allowance, Equality Challenge Unit, London, UK, 2012. 

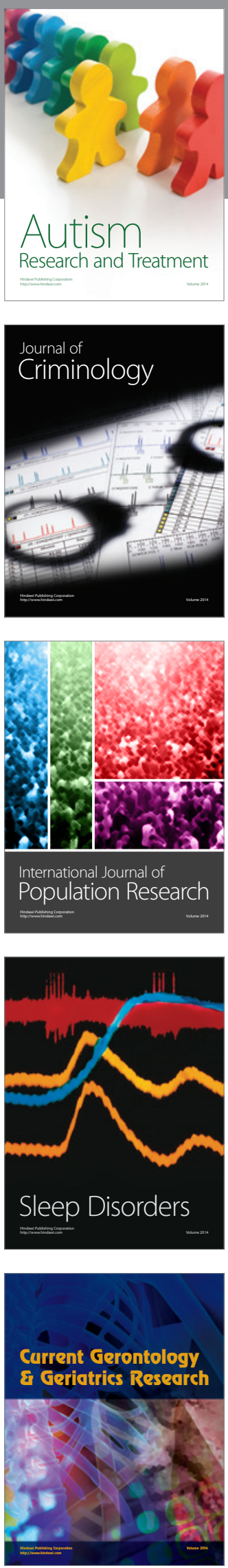
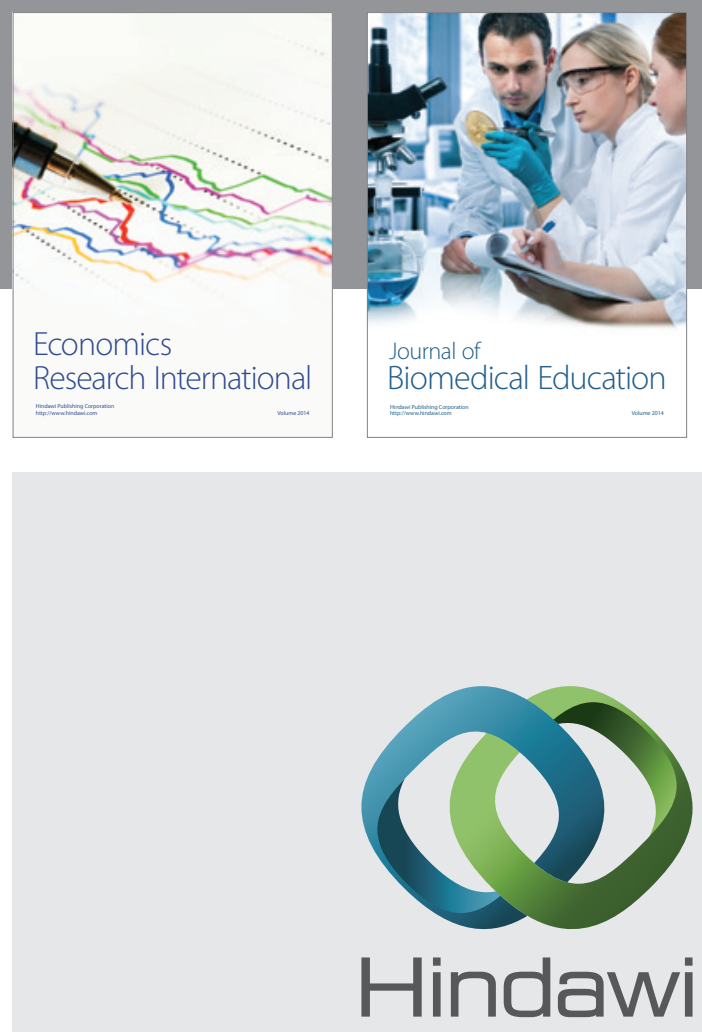

Submit your manuscripts at

http://www.hindawi.com
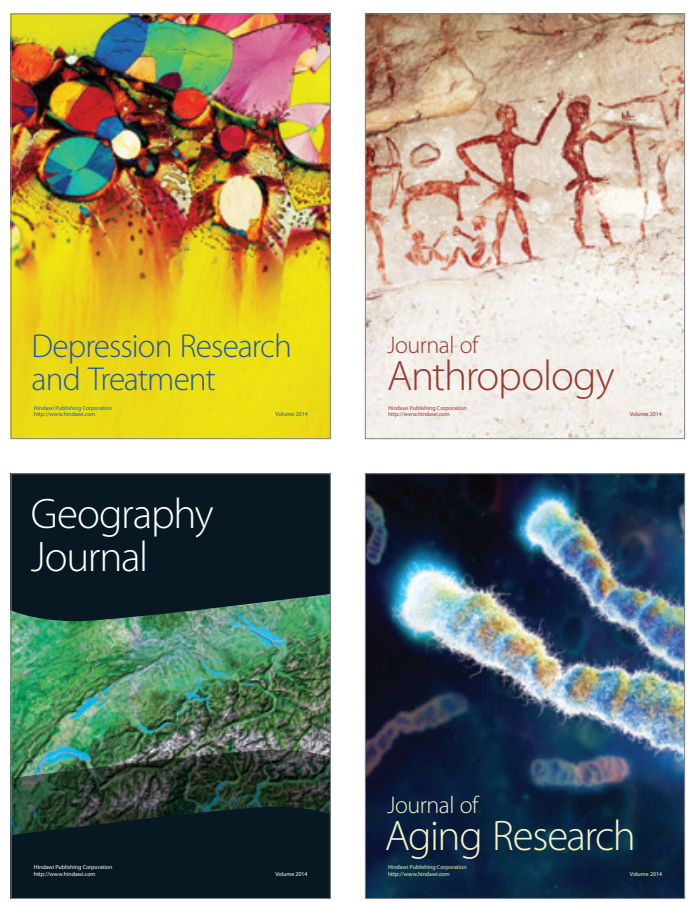
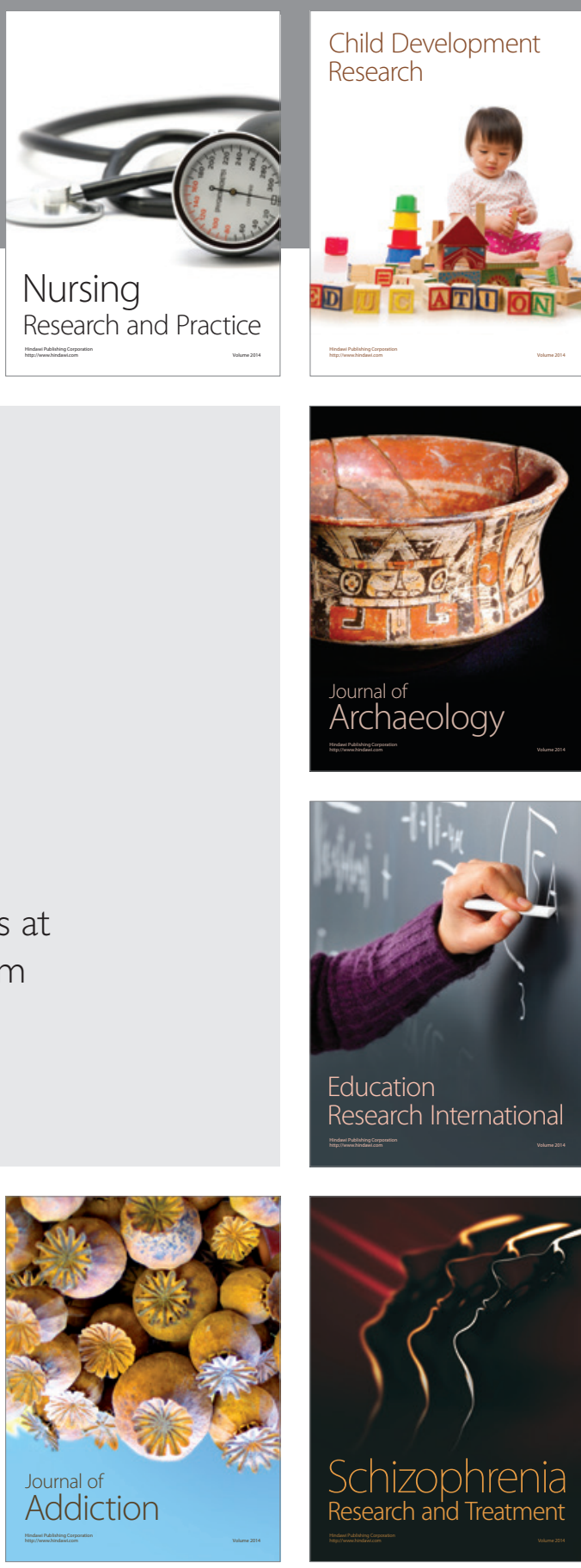

(D)
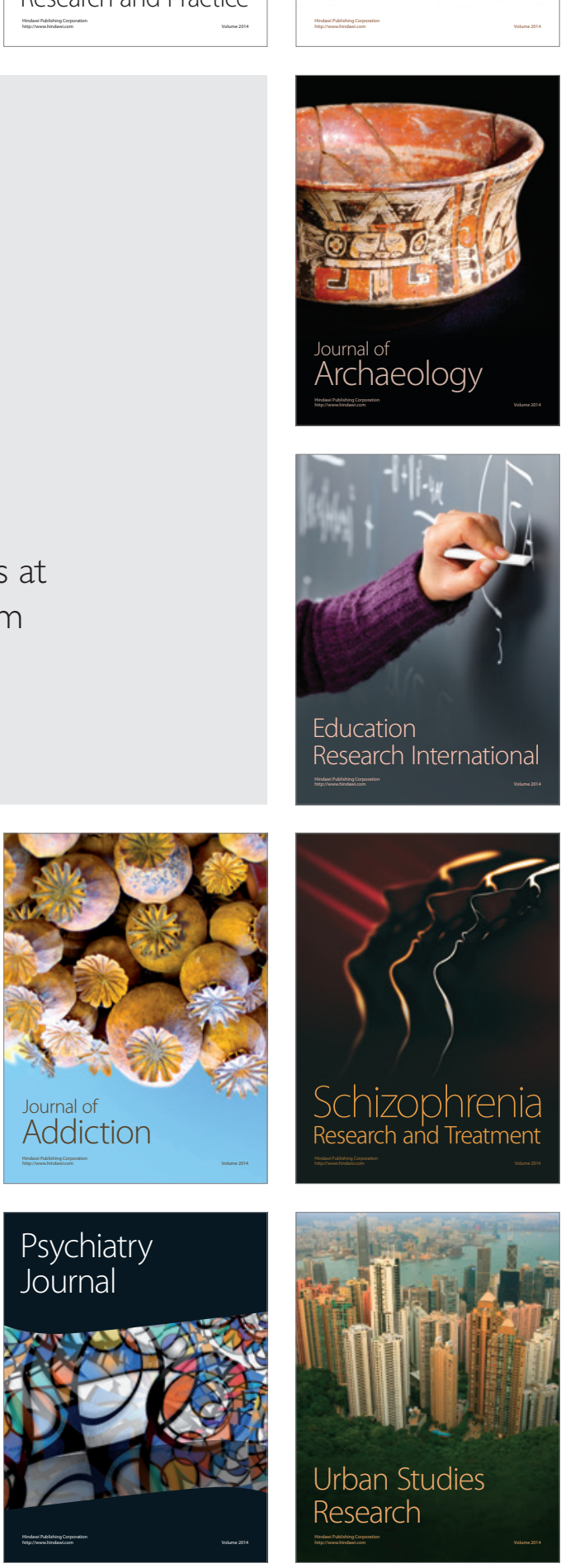